\title{
Polyhydroxyalkanoate Production by Pseudomonas putida KT217 on a Condensed Corn Solubles Based Medium Fed with Glycerol Water or Sunflower Soapstock
}

\author{
Jeremy Javers $^{1}$, William R. Gibbons ${ }^{1}$, Chinnadurai Karunanithy ${ }^{2 *}$ \\ ${ }^{1}$ Biology and Microbiology Department, South Dakota State University, Brookings, USA \\ ${ }^{2}$ Agricultural and Biosystems Engineering Department, South Dakota State University, Brookings, USA \\ Email: "karunanithy.chinnadu@sdstate.edu
}

Received February 16, 2012; revised April 30, 2012; accepted July 4, 2012

\begin{abstract}
Pseudomonas putida KT217 was grown on a complex medium comprised of co-products of the ethanol and biodiesel industries to assess the organism's capability to produce medium-chain-length polyhydroxyalkanoate (mcl-PHA). The growth phase was carried out in a medium containing $400 \mathrm{~g} / \mathrm{L}$ condensed corn solubles (CCS), supplemented with ammonium hydroxide as a nitrogen source. Following the exponential phase, co-products of the biodiesel industry (soapstock and glycerin) were fed into the reactor to trigger PHA production. When glycerin was added to the bioreactor (75 $\mathrm{g} / \mathrm{L}$ total addition), the final cell dry weight (CDW) and PHA content were $30 \mathrm{~g} / \mathrm{L}$ and 31\%, respectively. The monomeric composition in the PHA formed was relatively uniform throughout incubation with 3-hydroxydecanoate dominating. When a total of $153 \mathrm{~g} / \mathrm{L}$ of sunflower soapstock was added to the bioreactor in a fed-batch manner, the final CDW and PHA content were $17 \mathrm{~g} / \mathrm{L}$ and $17 \%$, respectively. Following addition of soapstock the monomeric composition of the polymer changed dramatically, with the 3-hydroxyoctanoate monomer becoming dominant and greater unsaturation present in the PHA.
\end{abstract}

Keywords: Polyhydroxyalkanoate; Pseudomonas putida; Condensed Corn Solubles; Glycerol; Soapstock

\section{Introduction}

Polyhydroxyalkanoates (PHAs) are a class of biodegradable polymers that have a wide range of physical properties depending upon the monomeric composition in the polymer [1-4]. For the past 30 years extensive PHA research has been conducted. With recent breakthroughs in PHA production technology and soaring oil prices, PHA and other biopolymers may be at the front of true commercial integration [5]. Biopolymers such as 1 3 propanediol, polylactic acid, starch based polymers, and PHA could capture as much as $1.5 \%-4.8 \%$ of the total plastics market ( 260 million tonnes/year). Production of PHA from renewable biomass is providing the "green" alternative to the pollution resulting from use on non-degradable plastics.

The costs of producing and recovering biodegradable polymers have been the key barrier to the marketplace. Numerous methods have been attempted to reduce the cost of extracting and purifying the polymer [6-13]. Similarly, several low cost substrates have been evaluated for PHA production, but low productivities typically

\footnotetext{
"Corresponding author.
}

result [14-30]. Solaiman et al. [31] reviewed the use of vegetable oils, animal fats, dairy whey, molasses, and meat and bone meal as feedstocks for PHA production. The ethanol and biodiesel production industries also generate large quantities of under-utilized byproducts which could be used for PHA production.

According to Renewable Fuels Association [32], the US ethanol production was 13507.9 million gallons from 204 plants and expected to increase by 522 million gallons on completion of 10 more plants under construction. Each gallon of ethanol accompanies with 5\% - 7\% of condensed solubles. The ethanol production co-product condensed corn solubles (CCS) is normally used in livestock feeds. CCS contains carbon and energy sources such as monosaccharides, oligosaccharides, organic acids, and glycerol, as well as a range of micronutrients and macronutrients such as zinc, iron, manganese, magnesium, sulfur, phosphate and nitrogen. Typically CCS is deficient in nitrogen, but due to its otherwise rich nutritional composition, CCS has been successfully used to grow a range of bacteria and fungi [33-35].

The co-products of biodiesel production include fattyacids, soapstock, and glycerol water. Soapstock is ob- 
tained from alkali refining of oilseeds and is composed of phosphorus lipids, hydrateable and non-saponifiable compounds, soaps of free fatty acids (FFA), vitamins A and E, and carotenoids pigments [36-39]. Soapstock is normally added back to oilseed meal for livestock feeding or is disposed of with little or no economic compensation [36].

Soapstock has been evaluated as a carbon and energy source to produce value added products via fermentation. Hesseltine and Koritala [40] evaluated a 2\% soybean soapstock medium for growth of 141 microorganisms, including yeast, fungi, bacteria, and actinomycetes. A non-disclosed Pseudomonas species grew at pH 8 - 11 . Later on Kaneshiro et al. [41] isolated a bacterium from manure compost (tentatively identified as a Sphingobacterium and designated strain NRRL B-14797) that grew on crude soybean soapstock and a soapstock extract, and produced 10(R)-hydroxystearic acid. They found that soapstock extracts were poor nutrients for growth, but were utilized better for hydroxy acid bioconversions than either crude soapstock or pure long chain fatty acids. This is most likely due to removal of some nutrients following purification of the fatty acids. Benincasa et al. [42,43] grew Pseudomonas aeruginosa LB1 aerobically on a defined liquid salts medium with $2.5 \%$ sunflower soapstock to produce rhamnolipids. Fed batch addition of soapstock gave the most favorable results, with $16 \mathrm{~g} / \mathrm{L}$ of product after $54 \mathrm{~h}$. Sunflower soapstock contains linoleic acid $50 \%$, oleic acid $25 \%$, palmitic acid $7 \%$, and stearic acid 4\%. Bednarski et al. [44] fed soapstock or post-refinery fatty acids to Candida antarctica and C.apicola to synthesize surfactants (glycolipids). Soapstock resulted in better glycolipid production than fatty acids (7.3 - 13.4 g/L vs 6.6 - $10.5 \mathrm{~g} / \mathrm{L}$, respectively), which was similar to the results observed in Pseudomonas aeruginosa LBI [41].

According to National Biodiesel Board [45], biodiesel production in the US has reached 1.1 billion gallons. Glycerol is a primarybyproduct of biodiesel production. Each gallon of biodiesel accompanies with $0.3 \mathrm{~kg}$ of glycerol is equivalent to $10 \%$, and this has triggered research to develop alternative uses, including microbial processes. For example, Flickinger and Perlman [46] converted glycerol to dihydroxyacetone with a Gluconobacter strain. Du-Pont created a process to produce 1 - 3 propanediol that channels glucose through glycerol [47]. It is possible for this product to be created directly from glycerol by microbial conversion via Clostridium strains [48]. The fermentation of glycerol by E. coli to end products such as ethanol, succinate, acetate, lactate, and hydrogen was found to be $\mathrm{pH}$ dependant [49]. Production of PHA from glycerol water has also been tested [21].

The combination of co-products from the ethanol and biodiesel industries could be used to create a medium to support growth and PHA accumulation. Our previous research revealed that Pseudomonas putida KT217 grew well on a medium comprised of CCS, supplemented with ammonium as a nitrogen source [50]. In the study reported herein we used this basal medium to test the effects of using a fed-batch feeding strategy with either glycerol water or sunflower derived soapstock to bolster PHA production.Trials were performed in an aerated benchtop reactor at the $2.35 \mathrm{~L}$ scale with soybean biodiesel-derived glycerin or sunflower-derived soapstock added fed-batch after 24 h to bolster PHA levels.

\section{Materials and Methods}

\subsection{Bacterial Strain, Maintenance, and Inoculum Preparation}

The bacterium used was $P$. putida KT217. Long term storage was via lyophilization, while short term storage was on tryptic soy agar (TSA) slants. The culture was routinely transferred in tryptic soy broth shake flasks incubated for $24-48 \mathrm{~h}$ at $30^{\circ} \mathrm{C}$ and $250 \mathrm{rpm}$. Subcultures were also transferred to shake flasks containing a CCS based medium (described below) at $\mathrm{pH}$ 7. A one percent inoculum of a $24 \mathrm{~h}$ culture was used to inoculate aerated fed-batch bioreactor trials.

\subsection{Experimental Design}

The basal CCS medium was prepared by mixing $1.2 \mathrm{~kg}$ of CCS from a dry grind ethanol plant with deionized water to a volume of $3 \mathrm{~L}$. The medium $\mathrm{pH}$ was adjusted to 7.3 with $30 \%$ ammonium hydroxide (after autoclaving the medium $\mathrm{pH}$ typically dropped to 6.7). The resulting mixture was centrifuged to remove suspended solids. The liquid portion was then filtered through Whatman 113 filter paper to remove most of the remaining suspended solids and oils. The medium ( 2.35 liters each) was then dispensed into a 5 L Bioflo III bioreactor (New Brunswick Scientific, Enfield, CT, USA)and autoclaved.

Trials were conducted aerobically in a fed-batch mode using $\mathrm{pH}$ control and dissolved oxygen (DO) was monitored. For $\mathrm{pH}$ control a saturated solution of sodium hydroxide and a $20 \%(\mathrm{v} / \mathrm{v})$ solution of sulfuric acid were used.

In the glycerol trials, following inoculation the culture was incubated for $96 \mathrm{~h}$ at $30^{\circ} \mathrm{C}$, with aeration at 1 $\mathrm{V} / \mathrm{V} / \mathrm{min}$ and agitation at $500 \mathrm{rpm}$. Clerol FBA 3107 (Cognis) was used as an antifoam agent in these trials as needed. In the soapstock trials the agitation and aeration had to be monitored to control foaming along with the antifoam.

After the initial $24 \mathrm{~h}$ growth phase, fed-batch additions of sterilize glycerol water (obtain from West Central Soy in Ralston, IA) or sunflower soapstock (obtained from 
Cargill) were delivered through the septum port on the fermentor with a sterile disposable $60 \mathrm{~mL}$ syringe. Glycerol water could be added as is, however the viscosity of soapstock was too high to deliver directly via syringe. Therefore, $40 \mathrm{~g}$ of Sunflower soapstock was diluted with deionized water to $150 \mathrm{~mL}$ total volume and autoclaved prior to feeding. Glycerol water was fed based upon HPLC data, to maintain glycerol levels between 5 and 35 $\mathrm{g} / \mathrm{L}$ during incubation. In total $240 \mathrm{~mL}$ of glycerol water was added between 24 and $70 \mathrm{~h}$. Soapstock was fed in response to dissolved oxygen levels rising above $10 \%$ following $24 \mathrm{~h}$ of cultivation, with $1350 \mathrm{~mL}$ (360 g) of soapstock solution added between 24 and $90 \mathrm{~h}$.

\subsection{Cell Dry Weight and Colony Forming Unit Measurement}

Cell dry weights (CDW) were obtained by harvesting 30 - $50 \mathrm{~mL}$ samples and centrifuging at $4000 \mathrm{rpm}$ for 30 min. Cell pellets were washed with $30 \mathrm{~mL}$ deionized water, re-centrifuged, and dried to a constant weight in a $60^{\circ} \mathrm{C}$ oven. Colony forming units (CFU) were determined by serial dilution and plating in triplicate on TSA.

\subsection{HPLC Analysis}

A Waters HPLC system (Waters Scientific, Milford, MA, USA) with refractive index detector was used to quantify sugars, organic acids, and glycerol in the culture samples. Prior to analysis samples were filtered through $0.2 \mu \mathrm{m}$ filters, then $50 \mu$ injections were made. The mobile phase was helium-degassed $4 \mathrm{mM}$ sulfuric acid at 0.6 $\mathrm{mL} / \mathrm{min}$, through a Biorad HPX-87H (Biorad, Hercules, CA, USA) organic acid analysis column operated at $65^{\circ} \mathrm{C}$. Standard solutions of maltose, glucose, lactic acid, acetic acid, propionic acid, succinic acid and glycerol were used for calibration.

\subsection{Nitrogen and Phosphorus Analysis}

Samples were assayed for nitrogen and phosphorus using Hach test kits and a Hach DR/2010 colorimeter (Hach, Loveland, CO, USA). Samples were filtered through 0.2 $\mu \mathrm{m}$ filters, then diluted 1:100 with double distilled water. Nitrogen was measured as ammonia using the Hach HCT 102 Unicel kit. Phosphorus was measured as free phosphates using of the Hach HCT 122 Unicel kit.

\subsection{PHA Analysis}

PHA concentrations were determined by first removing 30 - $50 \mathrm{~mL}$ samples, centrifuging at $4500 \mathrm{rpm}$ at $10^{\circ} \mathrm{C}$ for $30 \mathrm{~min}$, then washing and re-centrifuging the cells. Cell pellets were then lyophilized and homogenized prior to PHA extraction.

\subsection{PHA Extraction}

Standards are not readily available for each of the monomers present in the mcl-PHA produced by $P$. putida KT217. To overcome this, PHA was utilized from culture samples to create quantitative standards, following the methods describe by Foster et al. [51] and Kim [52]. Lyophilized cell samples from the final culture sample of the soapstock fed trial were extracted with a two-step supercritical fluid extraction [53]. In the first step, neat supercritical carbon dioxide was used to extract nonPHA lipids, followed by an ethanol modified step to extract PHA. Following centrifugation at $4500 \mathrm{rpm}$ to remove excess ethanol, PHA was dissolved in hot chloroform and precipitated by addition of ten volumes of cold methanol. This procedure of dissolving in chloroform and precipitation in cold methanol was repeated three times to purify the PHA. A portion of the purified PHA was dissolved in chloroform and used as a stock solution to prepare quantitative standards. These standards were prepared by hydrolyzing and derivatizing the methylesters of the respective monomers included in the PHA.

\subsection{PHA Hydrolysis and Derivitization}

Samples of lyophilized cells or purified PHA (10 - $60 \mathrm{mg}$ ) were digested in chloroform:methanol:sulfuric acid (50: 42.5:7.5 \% v/v) at $100^{\circ} \mathrm{C}$ for $4 \mathrm{~h}$, using benzoic acid as an internal standard [54-56]. Following digestion the mixture was washed with distilled water to remove excess sulfuric acid and methanol from the chloroform phase. This procedure creates methyl esters of the 3-hydroxy acids present in the PHA.

\subsection{PHA Analysis}

The created standards were analyzed on Thermo-Finnigan Trace GC/MS 2000. The column utilized was an RTx-5Sil MS (Restek, 30 meter, 0.25 mmID, $0.5 \mu \mathrm{m}$ df). The MS detector was utilized first for qualitative analysis of the monomers present in the samples. The FID detector was subsequently utilized for quantitative analysis of the PHA present in the samples. The total areas of the monomers present were correlated to the amount of PHA contained in three different levels of standard and normalized to the methyl ester of benzoic acid as an internal standard to create a calibration curve $\left(R^{2}=0.97-0.99\right)$. The digests of cell samples were then analyzed and the percentage of PHA contained within determined. For determination of the fractional analysis of PHA monomers, the area of the individual monomers was divided by the total area of the monomers.

\subsection{PHA Analysis by NMR Spectroscopy}

Samples obtained from SFE were dissolved in deuterated 
chloroform and ${ }^{13} \mathrm{C}$-NMR spectra were recorded on a Bruker $400 \mathrm{MHz}$ GRX NMR spectrometer (Bruker AXS, Inc, Madison, WI, USA) at a probe temperature of $27^{\circ} \mathrm{C}$.

\section{Results and Discussion}

\subsection{Growth on a CCS Medium with Fed-Batch Addition of Glycerol Water}

P. putida KT217 was grown in an aerated bioreactor on a $400 \mathrm{~g} / \mathrm{L}$ CCS-based medium supplemented with $2.2 \mathrm{~g} / \mathrm{L}$ ammonium hydroxide. The $400 \mathrm{~g} / \mathrm{L}$ CCS formulation had previously been identified as being optimal for rapid production of cell mass [50]. The average growth curve from two replications, in which glycerol water was added at 29, 34, 48, and 62 h, is shown in Figure 1.

Of the nutrients initially present in the CCS medium, $P$. putida KT217 first utilized the glucose $(2.1 \mathrm{~g} / \mathrm{L})$, succinic (2.9 g/L), lactic (4.6 g/L), acetic $(1.0 \mathrm{~g} / \mathrm{L})$, and propionic acids $(1.0 \mathrm{~g} / \mathrm{L})$ within $20 \mathrm{~h}$ (data not shown). Only after these carbon sources were depleted (at approximately $12 \mathrm{~h}$ ) did $P$. putida begin metabolizing glycerol, which fell from $39.3 \mathrm{~g} / \mathrm{L}$ initially to $8.4 \mathrm{~g} / \mathrm{L}$ at $28 \mathrm{~h}$. (Figure 1). Ammonia was exhausted by approximately $28 \mathrm{~h}$, which corresponded to the plateau in cell population $\left(6.4 \mathrm{e}^{10} \mathrm{CFU} / \mathrm{mL}\right)$ and $\mathrm{CDW}(\sim 23 \mathrm{~g} / \mathrm{L})$. The CDW included both cell mass and PHA, the latter of which had accumulated to $2 \%$.
The CDW was produced from $\sim 42 \mathrm{~g}$ of carbon, for a CDW yield of $\sim 0.55 \mathrm{~g}$ CDW/g carbon utilized. This CDW yield was slightly higher than theoretical and may be attributed to utilization of other medium components in CCS that were not detected by HPLC (e.g., oligosaccharides, amino acids). For example, in a phenol red broth medium with glucose as the carbon source $P$. putida KT217 was found to catalyze deamination of media proteins. It is possible that $P$. putida was able to use proteins and oils in CCS as carbon sources. Viable cell counts increase more rapidly than CDW due to the lower mass of individual cells during exponential growth. However, after the stationary phase was reached, CDW increased as cells filled with PHA.

At $28 \mathrm{~h}$, the first of four glycerol additions was made (Figure 1). These additions maintained glycerol levels between 8 - 35 g/L, and Figure 2 shows the glycerol utilization rate. At $28 \mathrm{~h}$, the glycerol utilization rate peaked at $2.87 \mathrm{~g} / \mathrm{L} / \mathrm{h}$. During the subsequent additions of glycerol, the utilization rate was maintained between 1 $2 \mathrm{~g} / \mathrm{L} / \mathrm{h}$. This lower rate was likely due to several factors including limitations of nitrogen and oxygen, and perhaps the increased salt concentration from the glycerol water. The glycerol utilization rate continued to decline, approaching $0.5 \mathrm{~g} / \mathrm{L} / \mathrm{h}$ at the end of fermentation, as cells filled with PHA.

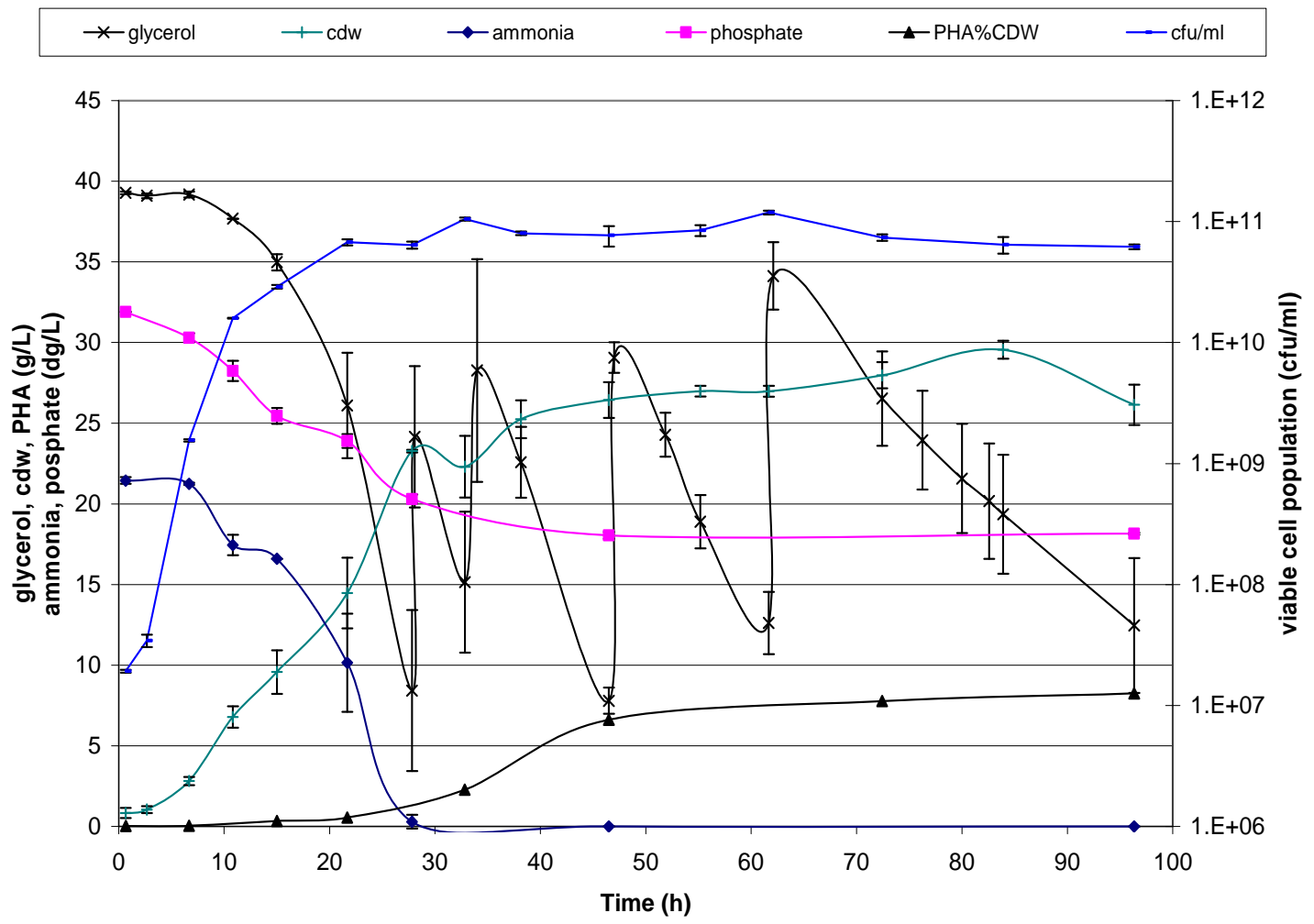

Figure 1. Growth and PHA production of P. putida KT217 on a CCS medium with fed-batch glycerol addition. Average of two fermentations with error bars representing standard deviation. 


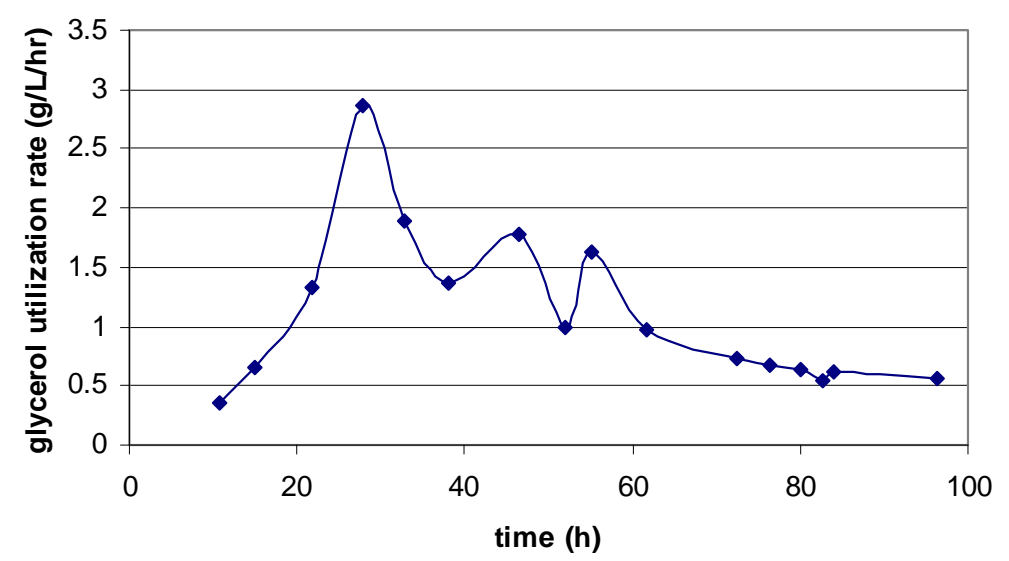

Figure 2. Glycerol utilization rate for $P$. putida KT217 grown on a CCS medium with fed-batch glycerol addition.

After $28 \mathrm{~h}$, theCDW continued to increase to around $30 \mathrm{~g} / \mathrm{L}$ at $85 \mathrm{~h}$. Since the viable cell population remained constant during this time period, the increase of $7 \mathrm{~g} / \mathrm{L}$ in CDW was primarily due to the accumulation of PHA. The increase in CDW of $7 \mathrm{~g} / \mathrm{L}$ from use of $\sim 65 \mathrm{~g} / \mathrm{L}$ of glycerol, corresponds to a CDW yield of $0.11 \mathrm{~g} / \mathrm{g}$ glycerol (CDW is sum of PHA and cell mass). This lower yield indicates that the majority of the glycerol was being used for maintenance energy in the culture. The various processes resulting in the utilization of carbon source for maintenance energy have been reviewed [57]. Additionally, an increase of PHA of $8 \mathrm{~g} / \mathrm{L}$ was measured by gas chromatography. This represents $31 \%$ of the total CDW. This is greater than the total increase in cell mass following limitation and may indicate that there was significant turnover of cell mass in the medium during this time resulting in a cell mass with varying PHA content.

The composition of the PHA produced by $P$. putida KT217 on a CCS medium fed with glycerol water changed with time as evidenced by gas chromatographic analysis (GC-MS and GC-FID). The overall concentration of 3-hydroxydodecanoate and 3-hydroxydodecenoate in the polymer decreased as the incubation proceeded, whereas the amount of 3-hydroxyhexanoate, 3hydroxyoctanoate, and 3-hydroxydecanoate all increased (Figure 3). Polymer composition was dominated throughout by 3-hydroxydecanoate which consistently represented more than $60 \%$ of the polymer. The concentration of 3-hydroxytetradecenoate, 3-hydroxytetradecanoate, and 3-hydroxyhexadecanoate were all detectable, but in very small concentrations (Figure 3). These conclusions are supported by ${ }^{13} \mathrm{C}$-NMR data shown in (Figure 4). Chemical shifts are similar to previously reported data for PHA analyzed in this method $[15,58,59]$.

\subsection{Growth on a CCS Medium with Fed-Batch Addition of Sunflower Soapstock}

P. putida KT217 was grown on 400 g/L CCS-based me- dium supplemented with ammonia as a nitrogen source (Figure 5). Carbon sources initially utilized for growth (glucose, lactic, succinic, acetic, and propionic acids) followed the same pattern as observed in Figure 1, and when these were depleted ( $\sim 20 \mathrm{~h})$, glycerol utilization began. Viable cell counts plateaued at $15 \mathrm{~h}$, but rose from 4.6e10 CFU/mL to $9.44 \mathrm{e} 10 \mathrm{CFU} / \mathrm{mL}$ by $40 \mathrm{~h}$. This corresponded to an increase in CDW from $\sim 11$ to $24 \mathrm{~g} / \mathrm{L}$ over the same period. Between 15 and $35 \mathrm{~h}$, the average glycerol utilization rate was $1.75 \mathrm{~g} / \mathrm{L} / \mathrm{h}$, which was comparable to the average rate observed $(1.4-2.9 \mathrm{~g} / \mathrm{L} / \mathrm{h})$ in the previous trials in the same time frame. Glycerol consumption continued until depletion at $39 \mathrm{~h}$, which corresponded to the peak CDW level. Ammonia depletion occurred at $32 \mathrm{~h}$. Following glycerol depletion in the medium the CDW decreased until 80 hours.

When glycerol fell to $10 \mathrm{~g} / \mathrm{L}$ ( $28 \mathrm{~h})$ sunflower soapstock additions were initiated. Because soapstock was viscous, $40 \mathrm{~g}$ of soapstock was blended with water to a volume of $150 \mathrm{~mL}$ prior to each addition. To compensate for this added volume, $150 \mathrm{~mL}$ of culture broth was removed prior to the diluted soapstock addition. It was not possible to monitor the level of soapstock, since it is a complex of several lipids. However, Lee et al. [60] previously reported that dissolved oxygen levels can be used to monitor carbon levels. Therefore when the dissolved oxygen saturation rose above $10 \%$, soapstock additions were made. This caused oxygen saturation to drop to near zero, and as it was consumed, oxygen saturation gradually increased. A total of $360 \mathrm{~g}$ of sunflower soapstock was added in a total volume of $1.35 \mathrm{~L}$, at $6-10 \mathrm{~h}$ intervals through $86 \mathrm{~h}$.

We had previously observed that $P$. putida KT217 could utilize the components in soapstock as a carbon and energy source during aerated shake flask trials in a defined medium (data not shown). The foaming problem in these trials was consistent with previous reports $[42,43]$. Soapstock also increased foaming in the aerated 


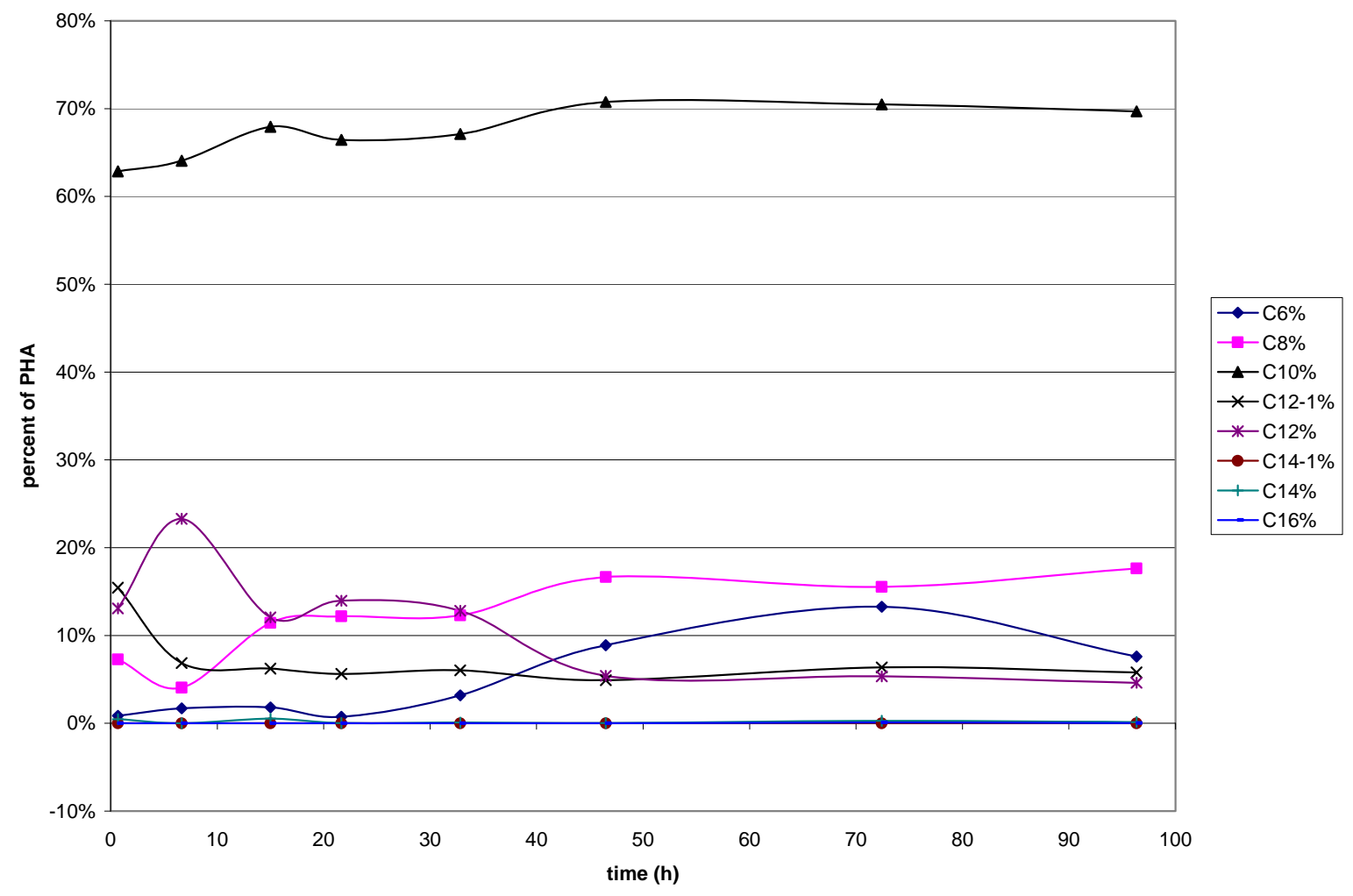

Figure 3. Time profile of monomeric composition determined by gas chromatography in PHA derived from fed-batch fermentation of $P$. putida KT217 on a syrup medium fed with glycerol water.

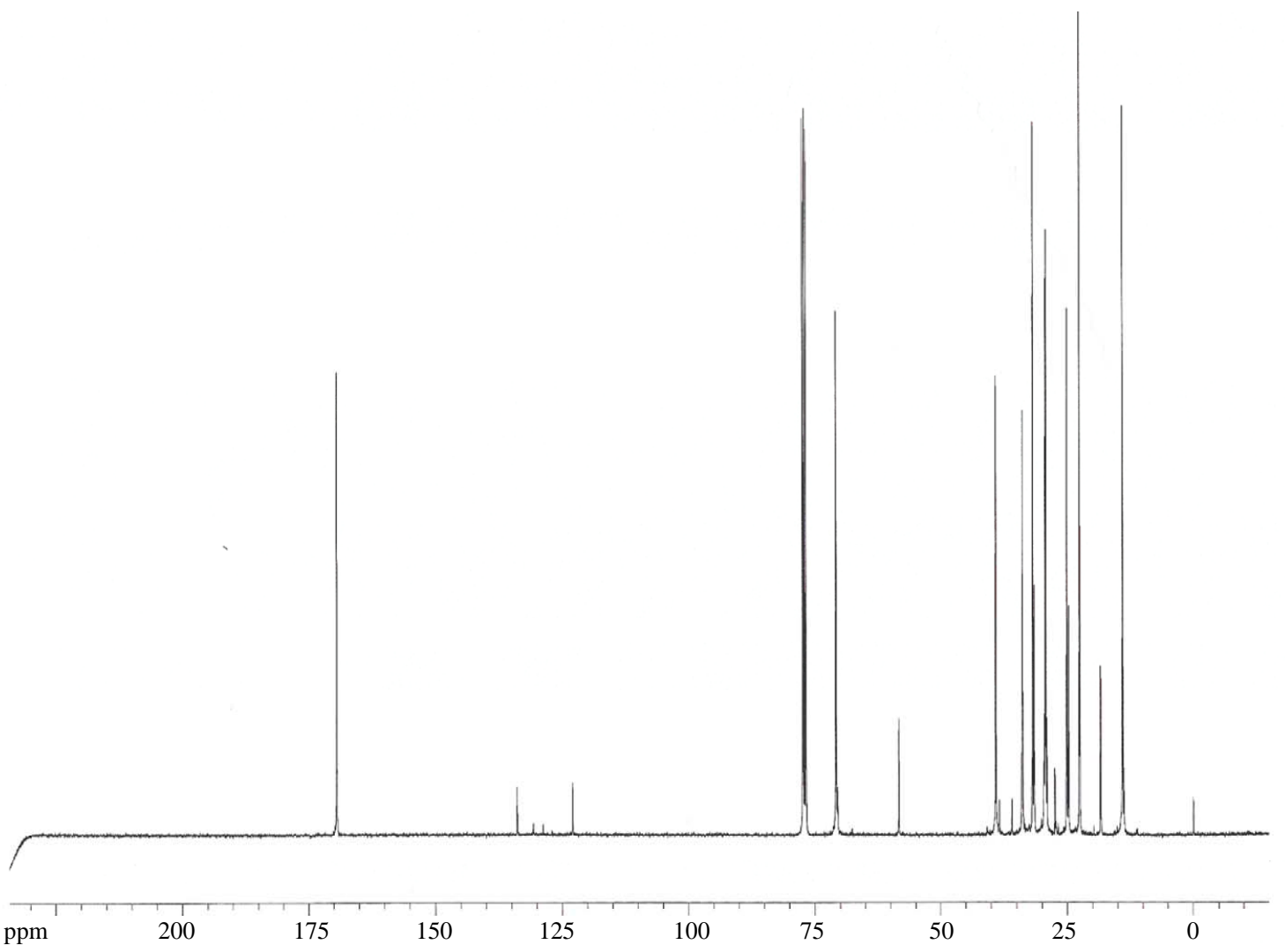

Figure 4. ${ }^{13} \mathrm{C}$-NMR of the PHA extracted from the final sample of the glycerol water fed batch fermentation. 


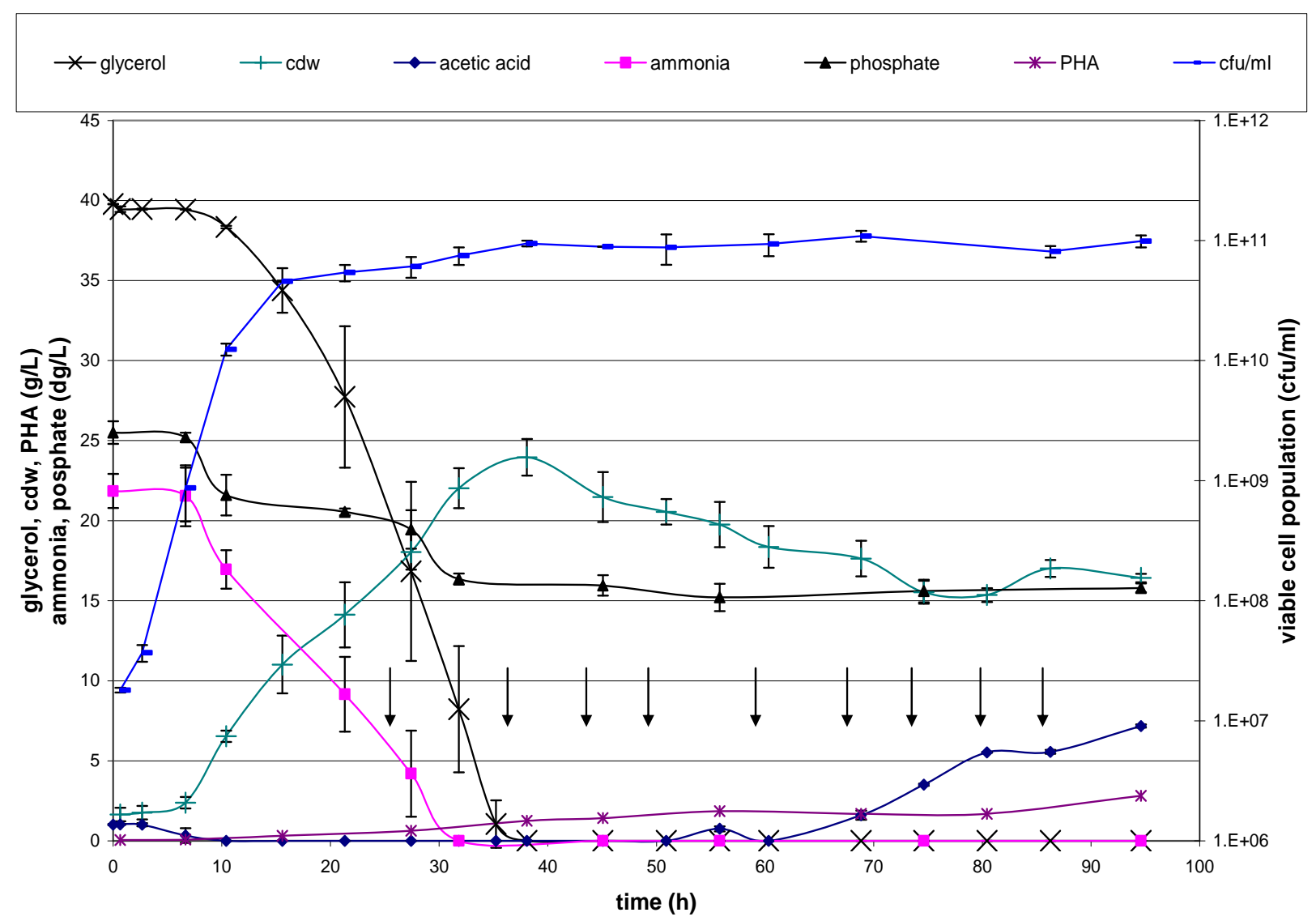

Figure 5. Growth and PHA production of $P$. putida KT217 on a CCS medium with fed-batch sunflower soapstock addition. Arrows indicate addition of $\mathbf{4 0}$ grams of sunflower soapstock. Average of two fermentations with error bars representing standard deviation.

bioreactor, even with antifoam addition. Therefore we reduced the aeration rate from $1 \mathrm{vvm}$ to $0.5 \mathrm{vvm}$.

After soapstock additions began, CDW decreased, even though viable cell populations remained steady. Evidently, the broth removed prior to soapstock additions contained cells at least partially filled with PHA, and these were replaced by newly formed cells that didn't contain as much PHA. This did not occur in the prior glycerol fed-batch process because only $240 \mathrm{~mL}$ of the concentrated (85\%) glycerol water was added, compared to the more dilute soapstock (50\% FFA) [37]. Acetic acid levels began to accumulate after $60 \mathrm{~h}$, eventually rising to $7 \mathrm{~g} / \mathrm{L}$. This was likely due to fatty acid degradation into acetyl-CoA, coupled with the decreased aeration rate and hence reduced acetic acid being excreted from the cells. It is likely that the Krebs cycle could not process acetyl-CoA at the same rate it was being produced, thus diverting some acetyl-CoA to acetic acid. This build up in acetyl-CoA may have activated the fatty acid synthesis pathway as well, explaining the increase in PHA.

PHA accumulated at a slow rate throughout incubation, reaching a concentration of $2.8 \mathrm{~g} / \mathrm{L}$ at the end, representing $17 \%$ of the total CDW. The composition of the PHA changed dramatically during incubation (Figure 6). Initially, the composition favored 3-hydroxydecanoate monomers due to the utilization of glycerol in the CCS. Following soapstock addition, polymer composition shifted towards 3-hydroxyoctanoate monomers. The final PHA contained 3-hydroxytetradecanoate and 3- hydroxytetradecanoate. ${ }^{13} \mathrm{C}-\mathrm{NMR}$ analysis of the final PHA produced during the incubation supported the information derived from GC-MS and GC-FID analysis showing an increase in unsaturation in the polymer (Figure 7). This is evident by examining the peaks in the chemical shift range of 120 - 150 ppm which has been shown previously $[15,55]$.

\section{Conclusions}

PHA production was observed over $100 \mathrm{~h}$ of aerated incubation when $P$. putida KT217 was grown on a basal medium of $400 \mathrm{~g} / \mathrm{L}$ CCS (wet basis) and $2.2 \mathrm{~g} / \mathrm{L}$ ammonium hydroxide, supplemented in fed-batch mode with either biodiesel co-products glycerol water (240 g) or soapstock (390 g). Foaming was a problem during soapstock trials, but was of less concern when using glycerol 


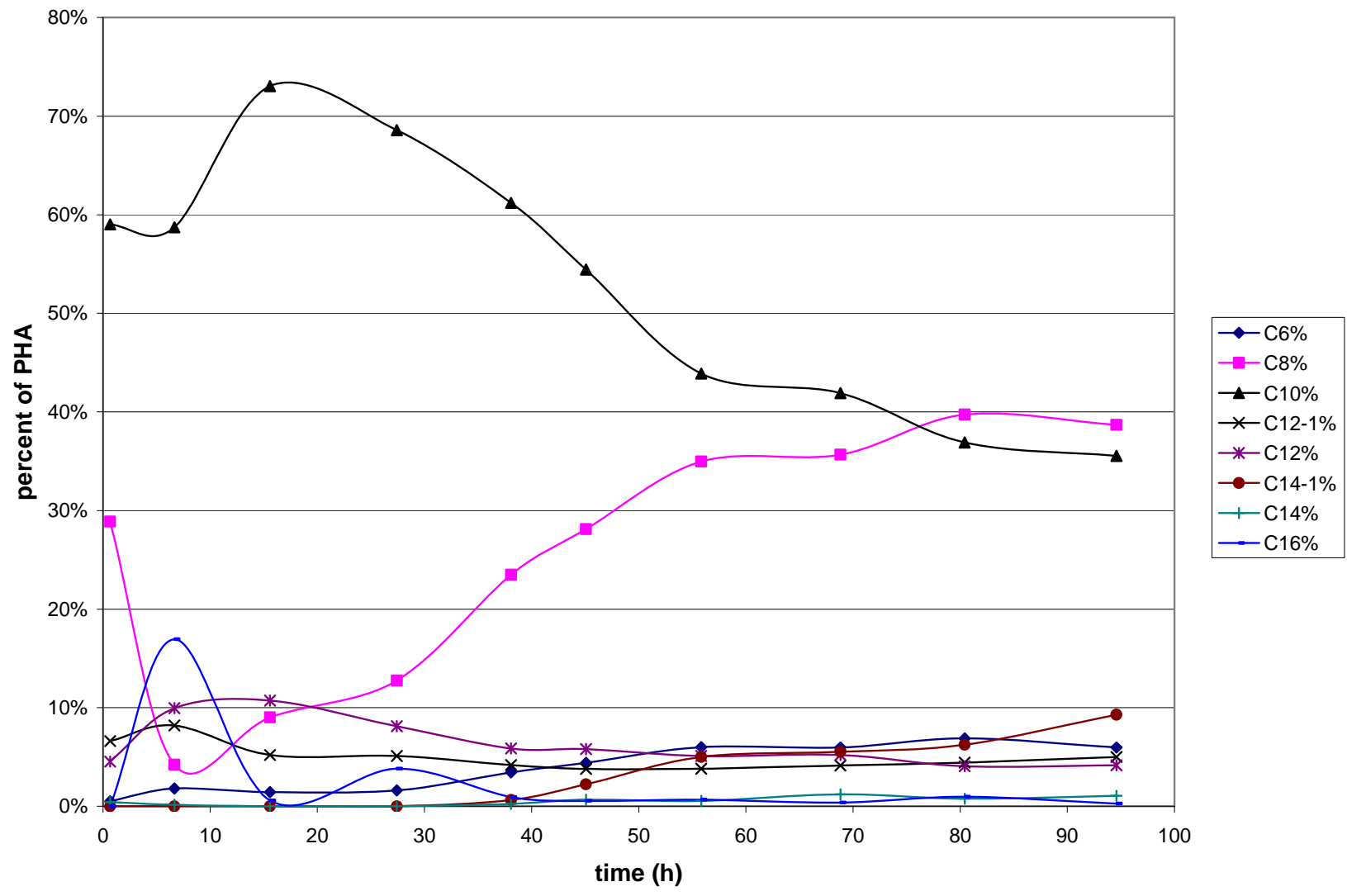

Figure 6. Time profile of monomeric composition determined by gas chromatography in PHA derived from fed-batch fermentation of $P$. putida KT217 on a syrup medium fed with sunflower soapstock.

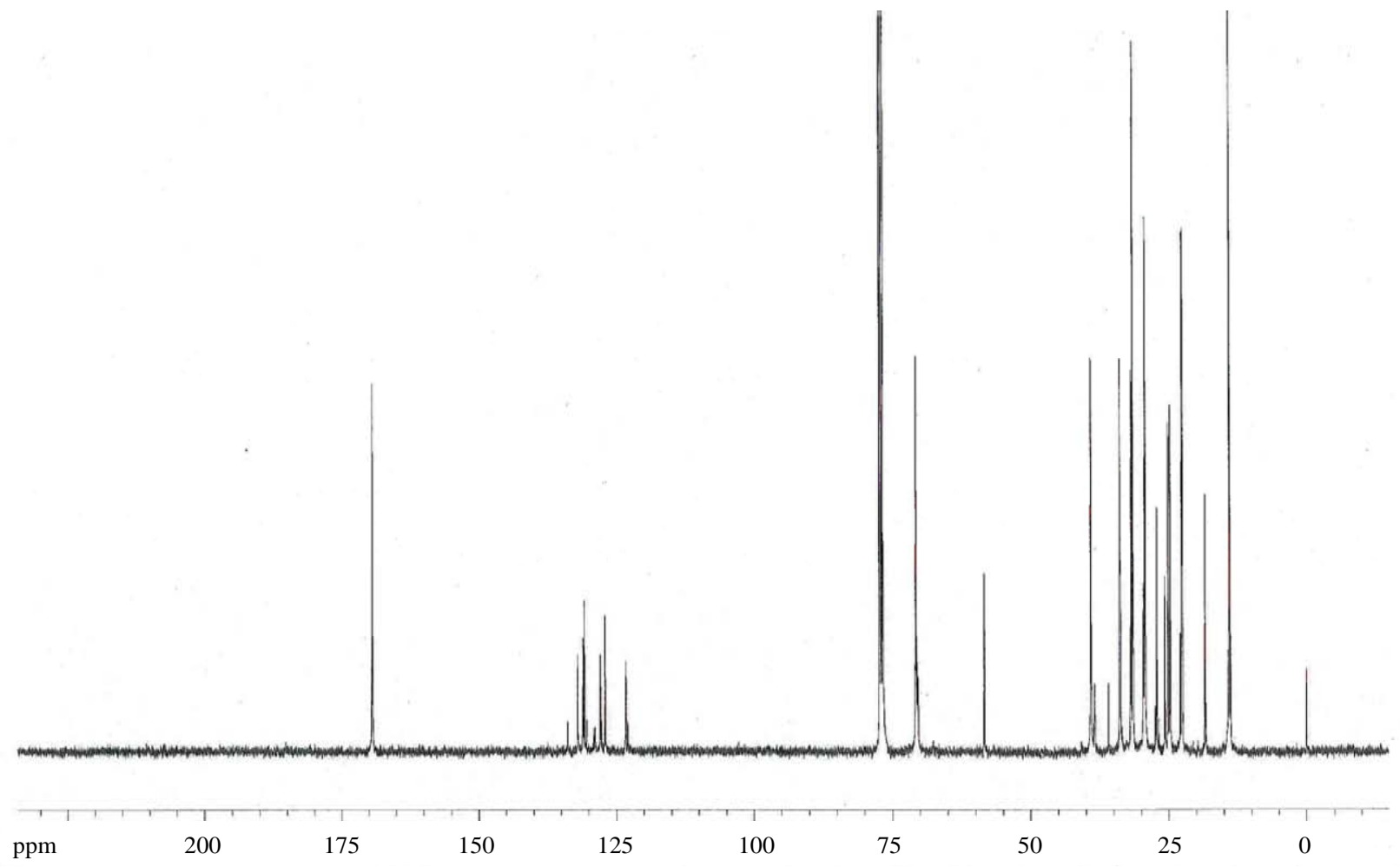

Figure 7. ${ }^{13} \mathrm{C}$-NMR of the PHA extracted from the final sample of the sunflower soapstock fed batch fermentation. 
water. Variations observed during replicate trials were likely caused by slight differences in aeration. $P$. putida was more efficient in using glycerol for cell growth (30 g/L CDW) and PHA content (31\%), with PHA primarily composed of 3-hydroxydecanoate generated by the de novo fatty acid synthesis pathway. This phenomenon was reported by Solaiman et al. [61] who observed that $P$. corrugata grown on soybean molasses carbohydrates also resulted in 3-hydroxy acyl-CoA monomers of this chain length. In contrast, sunflower soapstock resulted in only $17 \mathrm{~g} / \mathrm{L} \mathrm{CDW}$ and 17\% PHA content, with PHA composition shifting from 3-hydroxydecanoate to 3-hydroxyoctanoate over time due to $\beta$-oxidation, de novo fatty acid synthesis and fatty acid elongation pathways. This phenomenon was also noticed with $P$. corrugata when grown on a biodiesel co-product where the FFA's were preferentially utilized [62]. Soapstock derived PHA also showed an increase in unsaturation likely due to the unsaturation in the FFA contained in the soapstock.

The maximum concentration of PHA in cell mass that we observed was only $31 \%$, following a lengthy incubation when glycerol water was used as the carbon source. A majority of the carbon source fed to the $P$. putida was evidently used for maintenance energy (or possibly other products not detected). This low PHA level would likely lead to poor extraction economics, as current industrial processes target a 90\% PHA level. However these processes are primarily based on PHB-PHHx copolymers, and utilize starch-derived sugars for growth. Use of lower costs carbon sources may lead to more economically PHA production processes, however additional research is needed to improve microbe performance and feeding strategy.

\section{Acknowledgements}

Funding for this research was provided by the South Dakota Corn Utilization Council.

\section{REFERENCES}

[1] M. Avella, E. Martuscelli and M. Raimo, "Properties of Blends and Composites Based on Poly (3-Hydroxy) Butyrate (PHB) and Poly(3-Hydroxybutyrate-Hydroxyvalerate) (PHBV) Copolymers," Journal of Material Science, Vol. 35, No. 3, 2000, pp. 523-545. doi:10.1023/A:1004740522751

[2] K. Sudesh, H. Abe and Y. Doi, "Synthesis, Structure and Properties of Polyhydroxyalkanoates: Biological Polyesters," Progress in Polymer Science, Vol. 25, No. 10, 2000, pp. 1503-1555. doi:10.1016/S0079-6700(00)00035-6

[3] G. A. M. Van der Walle, G. J. M. de Koning, R. A. Weusthuis and G. Eggink, "Properties, Modifications, and Applications of Biopolyesters," Advances in Biochemical Engineering/Biotechnology, Vol. 71, 2001, pp. 264-293.
[4] N. Yoshie and Y. Inoue, "Chemical Composition Distribution of Bacterial Copolyesters," International Journal of Biology Macromolecules, Vol. 25, No. 1-3, 1999, pp. 193-200. doi:10.1016/S0141-8130(99)00034-3

[5] E. Chynoweth, "Spring Time for Biopolymers," Chemical Market Reporter, 2006, pp. 26-27.

[6] Y. Chen, H. Yang, Q. Zhou, J. Chen and G. Gu, "Cleaner Recovery of Poly (3-Hydroxybutyric Acid) Synthesized in Alcaligenes eutrophus," Process Biochemistry, Vol. 36, No. 6, 2001, pp. 501-506. doi:10.1016/S0032-9592(00)00225-9

[7] J. Choi and S. Y. Lee, "Efficient and Economical Recovery of Poly (3-Hydroxybutyrate) from Recombinant Escherichia coli by Simple Digestion with Chemicals," Biotechnology and Bioengineering, Vol. 62, No. 5, 1999, pp. 546-553. doi:10.1002/(SICI)1097-0290(19990305)62:5<546::AIDBIT6>3.0.CO;2-0

[8] S. K. Hahn, Y. K. Chang, B. S. Kim and H. N. Chang, Optimimization of Microbial Poly(3-Hydroxybutyrate) Recovery Using Dispersions of Sodium Hypochlorite Solution and Chloroform,” Biotechnology and Bioengineering, Vol. 44, No. 2, 1994, pp. 256-261. doi:10.1002/bit.260440215

[9] P. Hejazi, E. Vasheghani-Farahani and Y. Yamini, "Supercritical Fluid Disruption of Ralstonia eutropha for Poly (B-Hydroxybutyrate) Recovery,” Biotechnology Progress, Vol. 19, No. 5, 2003, pp. 1519-1523. doi:10.1021/bp034010q

[10] K. Khosravi-Darani, E. Vasheghani-Farahani, S. A. Shojaosadati and Y. Yamini, "Effect of Process Variables on Supercritical Fluid Disruption of Ralstonia eutropha Cells for Poly(R-hydroxybutyrate) Recovery,” Biotechnology Progress, Vol. 20, No. 6, 2004, pp. 1757-1765. doi:10.1021/bp0498037

[11] K. Khosravi-Darani, E. Vasheghani-Farahani, Y. Yamini and N. Bahramifar, "Solubility of Poly(B-hydroxybutyrate) in Supercritical Carbon Dioxide," Journal of Chemical Engineering Data, Vol. 48, No. 4, 2003, pp. 860863. doi:10.1021/je020168v

[12] M. Kim, K.-S. Cho, H. W. Ryu, E. G. Lee and Y. K. Chang, "Recovery of Poly (3-Hydroxybutyrate) from High Cell Density Culture of Ralstonia eutropha by Direct Addition of Sodium Dodecyl Sulfate," Biotechnology Letters, Vol. 25, No. 1, 2003, pp. 55-59. doi:10.1023/A:1021734216612

[13] J. A. Ramsay, E. Berger, R. Voyer, C. Chavarie and B. A. Ramsay, "Extraction of Poly(R-Hydroxybutyrate) Using Chlorinated Solvents," Biotechnology Technology, Vol. 8, No. 8, 1994, pp. 589-594. doi:10.1007/BF00152152

[14] W. S. Ahn, S. J. Park and S. Y. Lee, "Production of Poly (3-Hydroxybutyrate) from Whey by Cell Recycle FedBactch Culture of Recombinant Escherichia coli," Biotechnology Letters, Vol. 23, No. 3, 2001, pp. 235-240. doi:10.1023/A:1005633418161

[15] R. D. Ashby and T. A. Foglia, "Poly(hydroxyalkanoate) Biosynthesis from Triglyceride Substrates," Applied Microbiology and Biotechnology, Vol. 49, No. 4, 1998, pp. 


\section{1-437. doi:10.1007/s002530051194}

[16] E. Bormann and M. Roth, "The Production of Polyhydroxybutyrate by Methylobacterium rhodesianum and Ralstonia eutropha in Media Containing Glycerol and Casein Hydrolysates,” Biotechnology Letters, Vol. 21, No. 12, 1999, pp. 1059-1063. doi:10.1023/A:1005640712329

[17] G. Du, L. X. L. Chen and J. Yu, "High-Efficiency Production of Bioplastics from Biodegradeable Organic Solids,” Journal of Polymer Environment, Vol. 12, No. 2, 2004, pp. 89-94. doi:10.1023/B:JOOE.0000010054.58019.21

[18] G. Du and J. Yu, "Green Technology for Conversion of Food Scraps to Biodegradeable Thermoplastic Polyhydroxyalkanoates," Environment Science and Technology, Vol. 36, No. 24, 2002, pp. 5511-5516. doi:10.1021/es011110o

[19] B. Fuchtenbusch and A. Steinbuchel, "Biosynthesis of Polyhydroxyalkanoates from Low-Rank Coal Liquefaction Products by Pseudomonas oleovorans and Rhodococcus rubber," Applied Microbiology and Biotechnology, Vol. 52, No. 1, 1999, pp. 91-95. doi:10.1007/s002530051492

[20] T. M. Keenan, S. W. Tanenbaum, A. J. Stipanovic and J. P. Nakas, "Production and Characterization of Poly-BHydroxyalkanoate Copolymers from Burkholderia cepacia Utilizing Xylose and Levulinic Acid,” Biotechnology Progress, Vol. 20, No. 6, 2004, pp. 1697-1704. doi:10.1021/bp049873d

[21] M. Koller, R. Bona, G. Braunegg, C. Hermann, P. Horvat, M. Kroutil, J. Martinz, J. Neto, L. Pereira and P. Varila, "Production of Polyhydroxyalkanoates from Agricultural Waste and Surplus Materials,” Biomacromolecules, Vol. 6, No. 2, 2005, pp. 561-565. doi:10.1021/bm049478b

[22] F. C. Oliveira, D. M. G. Freire and L. R. Castilho, "Production of Poly (3-Hydroxybutyrate) by Solid-State Fermentation with Ralstonia eutropha," Biotechnology Letters, Vol. 26, No. 24, 2004, pp. 1851-1855. doi:10.1007/s10529-004-5315-0

[23] M. Purushothaman, R. K. I. Anderson, S. Narayana and V. K. Jayaraman, "Industrial Byproducts as Cheaper Medium Components Influencing the Production of Polyhydroxyalkanoates (PHA)-Biodegradeable Plastics," Bioprocess Biosystems Engineering, Vol. 24, No. 3, 2001, pp. 131-136. doi:10.1007/s004490100240

[24] R. G. Ribera, M. Monteoliva-Sanchez and A. RamosCormenzana, "Production of Polyhidroxyalkanoates by Pseudomonas putida KT2442 Harboring pSK2665 in Wastewater from Olive Oil Mills (Alpechin),” Electronic Journal of Biotechnology, Vol. 4, No. 2, 2001, pp. 116119.

[25] I. K. P. Tan, K. S. Kumar, M. Theanmalar, S. N. Gan and B. Gordon III, "Saponified Palm Kernel Oil and Its Major Free Fatty Acids as Carbon Substrates for the Production of polyhydroxyalkanoates in Pseudomonas putida PGA1," Applied Microbiology and Biotechnology, Vol. 47, No. 3, 1997, pp. 207-211. doi:10.1007/s002530050914

[26] T. G. Volova and N. A. Voinov, "Study of a Ralstoniaeutropha Culture Producing Polyhydroxyalkanoates on
Products of Coal Processing," Applied Biochemistry and Microbiology, Vol. 40, No. 3, 2004, pp. 296-300. doi:10.1023/B:ABIM.0000025946.47013.03

[27] P. G. Ward, G. de Roo and K. E. O’Connor, “Accumulation of Polyhydroxyalkanoate from Styrene and Phenylacetic Acid by Pseudomonas putida CA-3," Applied Environmental Microbiology, Vol. 71, No. 4, 2005, pp. 2046 2052. doi:10.1128/AEM.71.4.2046-2052.2005

[28] J. Yu, "Production of PHA from Starchy Wastewater via Organic Acids,” Journal of Biotechnology, Vol. 86, No. 2, 2001, pp. 105-112. doi:10.1016/S0168-1656(00)00405-3

[29] P. H. F. Yu, H. Chua, A. L. Huang, W. H. Lo and K. P. Ho, "Transformation of Industrial Food Wastes into Polyhydroxyalkanoates," Water Science and Technology, Vol. 40, No. 1, 1999, pp. 365-370. doi:10.1016/S0273-1223(99)00402-3

[30] S. Zhang, O. Norrlow, J. Wawrzynczyk and E. S. Dey, "Poly(3-Hydroxybutyrate) Biosynthesis in the Biofilm of Alcaligenes eutrophus, Using Glucose Enzymatically Released from Pulp Fiber Sludge,” Applied Environmental Microbiology, Vol. 70, No. 11, 2004, pp. 6776-6782. doi:10.1128/AEM.70.11.6776-6782.2004

[31] D. K. Y. Solaiman, R. D. Ashby, T. A. Foglia and W. N. Marmer, "Conversion of Agricultural Feedstock and Coproducts into Poly(Hydroxyalkanoates)," Applied Microbiology and Biotechnology, Vol. 71, No. 6, 2006, pp. 783789. doi:10.1007/s00253-006-0451-1

[32] Renewable Fuel Association, "Ethanol Industry Overview," 2012. http://www.ethanolrfa.org/pages/statistics

[33] S. A. Bock, S. L. Fox and W. R. Gibbons, "Development of a Low Cost, Industrially Suitable Medium for Production of Acetic Acid from Glucose by Clostridium thermoaceticum," Biotechnology and Applied Biochemistry, Vol. 25, 1997, pp. 117-125.

[34] A. Fosmer, W. R. Gibbons and N. Heisel, "Reducing the Cost of Scleroglucan Production by Use of a Condensed Corn Solubles Medium," Journal of Biotechnology Research, Vol. 2, 2010, pp. 131-143.

[35] V. Hof, W. R. Gibbons, N. Bauer and T. West, "Development of a Low-Cost Medium for Producing Gellan from Sphingomonas paucimobilis," Journal of Biotechnology Research, Vol. 2, 2010, pp. 67-78.

[36] M. S. Kuk and A. G. Ballew, "The Potential of Soapstock-Derived Film: Cottonseed and Safflower," Journal of the American Oil Chemists' Society, Vol. 76, No. 11, 1999, pp. 1387-1392. doi:10.1007/s11746-999-0155-7

[37] K. Waliszewski, "Fatty Acid Composition of Different Oils and Their Soapstocks," Nutrition Reports International, Vol. 35, 1987, pp. 87-91.

[38] J. B. Woerfel, "Processing and Utilization of By-Products from Soy Oil Processing," Journal of the American Oil Chemists' Society, Vol. 58, No. 3, 1981, pp. 188-191. doi:10.1007/BF02582333

[39] J. B. Woerfel, “Alternatives for Processing of Soapstock,” Journal of the American Oil Chemists' Society, Vol. 60, No. 2, 1983, pp. 310-313. doi:10.1007/BF02543509

[40] C. W. Hesseltine and S. Koritala, "Screening of Industrial 
Micro-Organisms for Growth on Soybean Soapstock," Process Biochemistry, Vol. 22, 1987, pp. 9-12.

[41] T. Kaneshiro, J.-K. Huang, D. Weisleder and M. O. Bagby, "10(R)-Hydroxystearic Acid Production by a Novel Microbe, NRRL B-14797, Isolated from Compost,” Journal of Industrial Microbiology, Vol. 13, No. 6, 1994, pp. 351-355. doi:10.1007/BF01577218

[42] M. Benincasa, J. Contiero, M. A. Manresa and I. O. Moraes, "Rhamnolipid Production by Pseudomonas Aeruginosa LBI Growing on Soapstock as the Sole Carbon Source," Journal of Food Engineering, Vol. 54, No. 4, 2002, pp. 283-288. doi:10.1016/S0260-8774(01)00214-X

[43] M. Benincasa, A. Abalos, I. Oliveira and A. Manresa, "Chemical Structure, Surface Properties and Biological Activities of the Biosurfactant Produced by Pseudomonas Aeruginosa LBI from Soapstock," Antonie van Leewenhoek, Vol. 85, No. 1, 2004, pp. 1-8. doi:10.1023/B:ANTO.0000020148.45523.41

[44] W. Bednarski, M. Adamczak, J. Tomasik and M. Paszczyk, "Application of Oil Refinery Waste in the Biosynthesis of Glycolipids by Yeast,” Bioresource Technology, Vol. 95, No. 1, 2004, pp. 15-18. doi:10.1016/j.biortech.2004.01.009

[45] National Biodiesel Board, "Biodiesel Production Exceeds 1 Billion Gallons, Policies Prove Effective,” 2012. http://www.biodiesel.org/news/bulletin/\#1

[46] M. C. Flickinger and D. Perlman, “Application of Oxygen-Enriched Aeration in the Conversion of Glycerol to Dihydroxyacetone by Gluconobacter melanogenus IFO 3293,” Applied Environment Microbiology, Vol. 33, 1977, pp. 706-712.

[47] S. R. Morrissey, "Building on Success," Chemical Engineering News, Vol. 84, No. 19, 2006, pp. 39-40. doi:10.1021/cen-v084n019.p039

[48] V. Stefuca, I. Vostiar, J. Sefcovicova, J. Katrlik, V. Mastihuba, M. Greifova and P. Gemeiner, "Development of Enzyme Flow Calorimeter System for Monitoring of Microbial Glycerol Conversion,” Applied Microbiology and Biotechnology, Vol. 72, No. 6, 2006, pp. 1170-1175. doi:10.1007/s00253-006-0420-8

[49] Y. Dharmadi, A. Murarka and R. Ganzalez, "Anaerobic Fermentation of Glycerol by Escherichia coli: A New Platform for Metabolic Engineering," Biotechnology and Bioengineering, Vol. 94, No. 5, 2006, pp. 821-829. doi:10.1002/bit.21025

[50] J. Javers, W. Gibbons and C. Karunanithy, "Optimizing a Nitrogen-Supplemented, Condensed Corn Solubles Medium for Growth of the Polyhydroxyalkanoate Producer Pseudomonas putida KT217," Industrial Biotechnology, 2012, in Review.

[51] L. J. R. Foster, A. Saufi and P. J. Holden, "Environmental Concentrations of Polyhydroxyalkanoates and Their Potential as Bioindicators of Pollution," Biotechnology Letters, Vol. 23, No. 11, 2001, pp. 893-898. doi:10.1023/A:1010528229685
[52] B. S. Kim, "Production of Medium Chain Length Polyhydroxyalkanoates by Fed-Batch Culture of Pseudomonas oleovorans," Biotechnology Letters, Vol. 24, No. 2, 2002, pp. 125-130. doi:10.1023/A:1013898504895

[53] J. E. Javers, W. R. Gibbons, F. Halaweish and D. E. Raynie, "Isolation of Medium Chain Length Polyhydroxyalkanoates from Pseudomonas resinovorans by Ethanol-Modified Supercritical Fluid Extraction,” Journal of the American Oil Chemists' Society, 2012, in Review.

[54] H. Brandl, R. A. Gross, R. W. Lenz and R. C. Fuller, "Pseudomonas oleovorans as a Source of Poly(B-Hydroxyalkanoates) for Potential as Biodegradeable Polyesters,” Applied Environment Microbiology, Vol. 54, No. 8, 1988, pp. 1977-1982.

[55] G. N. M. Huijberts, H. van der Wal, C. Wilkinson and G. Eggink, "Gas-Chromatographic Analysis of Poly(3-Hydroxyalkanoates) in Bacteria," Biotechnology Technology, Vol. 8, No. 3, 1994, pp. 197-192. doi:10.1007/BF00161588

[56] R. G. Lageveen, G. W. Huisman, H. Preusting, P. Ketelaar, G. Eggink and B. Witholt, "Formation of Polyexsters by Pseudomonas oleovorans: Effect of Substrates on Formation and Composition of Poly-(R)-3-Hydroxyalkenoates," Applied Environment and Microbiology, Vol. 54, No. 12, 1988, pp. 2924-2932.

[57] J. B. Russel and G. M. Cook, "Energetics of Bacterial Growth: Balance of Anabolic and Catabolic Reactions," Microbiology Review, Vol. 59, 1995, pp. 48-62.

[58] P. De Waard, H. van der Wal, G. N. M. Huijberts and G. Eggink, "Heteronuclear NMR Analysis of Unsaturated Fatty Acids in Poly (3-Hydroxyalkanoates): Study of BetaOxidation in Pseudomonas putida," Journal of Biology Chemistry, Vol. 268, No. 1, 1993, pp. 315-319.

[59] G. N. M. Huijberts, T. C. de Rijk, P. de Waard and G. Eggink, ${ }^{13} \mathrm{C}$ Nuclear Magnetic Resonance Studies of Pseudomonas putida Fatty Acid Metabolic Routes Involved in Poly(3-Hydroxyalkanoate) Synthesis," Journal of Bacteriology, Vol. 176, No. 6, 1994, pp. 1661-1666.

[60] S. H. Lee, D. H. Oh, W. S. Ahn, Y. Lee, J.-I. Choi and S. Y. Lee, "Production of Poly (3-Hydroxybutyrat-co-3-hydroxyhexanoate) by High-Cell-Density Cultiviation of Aeromonas hydrophila," Biotechnology and Bioengineering, Vol. 67, No. 2, 2000, pp. 240-244. doi:10.1002/(SICI)1097-0290(20000120)67:2<240::AIDBIT14>3.0.CO;2-F

[61] D. K. Y. Solaiman, R. D. Ashby, A. T. Hotchkiss and T. A. Foglia, "Biosynthesis of Medium-Chain-Length Poly (hydroxyalkanoates) from Soy Molasses,” Biotechnology Letters, Vol. 28, No. 3, 2006, pp. 157-162. doi:10.1007/s10529-005-5329-2

[62] R. D. Ashby, D. K. Y. Solaiman and T. A. Foglia, “Bacterial Poly(Hydroxyalkanoate) Polymer Production from the Biodiesel Co-Product Stream,” Journal of Polymer Environment, Vol. 12, No. 3, 2004, pp. 105-112. doi:10.1023/B:JOOE.0000038541.54263.d9 